\section{$\underset{\substack{\text { hommes } \\ \text { \& migrations }}}{ }$}

\section{Hommes \& migrations}

Revue française de référence sur les dynamiques

migratoires

$1310 \mid 2015$

Fashion Mix

\title{
La Turquie face au centenaire du génocide des Arméniens
}

\section{Ali Kazancigil}

\section{OpenEdition}

\section{Journals}

Édition électronique

URL : http://journals.openedition.org/hommesmigrations/3192

DOI : 10.4000/hommesmigrations.3192

ISSN : 2262-3353

Éditeur

Musée national de l'histoire de l'immigration

\section{Édition imprimée}

Date de publication : 1 avril 2015

Pagination : 167-170

ISBN : 978-2-919040-31-5

ISSN : $1142-852 X$

\section{Référence électronique}

Ali Kazancigil, «La Turquie face au centenaire du génocide des Arméniens », Hommes \& migrations [En ligne], 1310 | 2015, mis en ligne le 14 décembre 2015, consulté le 14 septembre 2020. URL : http:// journals.openedition.org/hommesmigrations/3192 


\section{REPÉRAGE}

\section{LA TURQUIE FACE AU CENTENAIRE DU GÉNOCIDE DES ARMÉNIENS}

Par ALI KAZANCIGIL, politologue, universitaire et ancien correspondant du journal Le Monde à Ankara.

L 'extermination de plus d'un million d'Arméniens ottomans, en 1915-1916, par le gouvernement dirigé par le Comité Union et Progrès, le parti des Jeunes-Turcs, a été érigée en un tabou absolu, qui devint un des piliers de l'idéologie nationaliste de la République, créée en 1923.

Pourquoi un tel génocide, minutieusement planifié afin d'éliminer un peuple et une civilisation plusieurs fois millénaires? Le facteur principal n'était pas d'ordre racial, comme ce sera le cas dans le génocide des Juifs, mais géopolitique et idéologique. Traumatisés par la perte des dernières possessions ottomanes dans les Balkans, à la suite des Guerres balkaniques de 1912-1913 et acquis au nationalisme turc naissant - le Turquisme -, les dirigeants Jeunes-Turcs envisageaient la création d'un empire panturc, à la place de l'Empire ottoman cosmopolite, en train de sombrer. Selon le nationalisme radical, social-darwiniste qui les animait, les territoires de ce nouvel empire devaient inclure l'Anatolie débarrassée de ses populations non -musulmanes (environ $40 \%$, à l'époque), de même que les pays turcophones du Caucase (Azerbaïdjan) et de l'Asie centrale (Turkménistan, Kazakhstan, Ouzbékistan et Kirghizistan). Or, l'édification de cet empire panturc risquait d'être entravée par un projet envisagé au Congrès de Berlin de 1878 mais jamais concrétisé : la création d'un État arménien indépendant, en Anatolie orien- tale. En effet, l'Angleterre et la France, en guerre contre l'allié de l'Allemagne qu'était devenu l'Empire ottoman depuis 1914, réfléchissaient à la réalisation de ce projet. D'où, l'idée criminelle d'éradiquer les Arméniens anatoliens.

\section{Le négationnisme de l'État turc}

Sur le génocide de 1915, il existe une historiographie très vaste et de grande qualité, grâce aux travaux d'historiens de divers pays, y compris de Turquie. Or l'État turc ignore cette littérature scientifique internationale. II a inventé et imposé à la société, aux médias et inscrit dans les manuels scolaires un récit qui présente ce qui s'est passé en 1915-1916 comme un épisode malheureux de la Première Guerre mondiale, au cours duquel il y aurait eu des massacres mutuels entre des Arméniens qui aidaient les armées russes ayant pénétré les régions nord-est de l'Anatolie et des Turcs qui voulaient les en empêcher. Toujours selon cette histoire officielle, les autorités ottomanes auraient alors décidé de déporter les Arméniens vers la Syrie. De nombreux Arméniens seraient morts durant la déportation, à cause des conditions difficiles de ces déplacements. Ce récit n'est pas crédible. Si les exterminations de 19151916 étaient liées uniquement à des événements 


\section{REPÉRAGE}

survenus en Anatolie orientale, pourquoi a-t-on envoyé à la mort des populations arméniennes vivant en Anatolie occidentale?

À cet égard, citons l'exemple de la ville de Bursa, située au nord-ouest du pays : selon le dernier recensement ottoman, au début $d u X X$ siècle, 44 ooo Arméniens habitaient à Bursa. En revanche, le premier recensement sous la République, peu de temps après sa création, montrait que seuls 4 Arméniens y résidaient ! Quant à la déportation, tous les témoignages dignes de confiance de l'époque

Désormais, la référence au "génocide arménien" et

le débat à ce sujet dans

l'espace public, qui étaient

considérés comme une

“insulte à l’identité turque" selon l'article 301

du Code pénal, ne posent plus de problème. indiquent que les hommes étaient assassinés systématiquement et beaucoup de femmes et enfants tués. L'État turc est devenu l'otage de ses propres contre-vérités. Contre toute logique et toute éthique, il s'est enfermé dans son négationnisme. L'imposition de ces mensonges et d'un tabou sur l'Histoire a toujours été un puissant obstacle à la démocratie et à l'État de droit. Malgré un système parlementaire pluraliste et des élections libres, c'est un autoritarisme nationaliste-laïque, incarné notamment par la bureaucratie militaire, qui a prédominé.

Avec l'arrivée au pouvoir, en novembre 2002, de I'AKP (Parti de la justice et du développement) de Recep Tayyip Erdogan, I'autoritarisme nationaliste-laïque n'a pas disparu, mais il a été marginalisé. L'AKP se réclamait alors d'une démocratie musulmane s'inspirant de la démocratie chrétienne européenne. D'importantes réformes furent introduites, confortant la démocratie, les libertés et l'État de droit, dans le contexte de la préparation des négociations d'adhésion à I'Union européenne. Celles-ci débutèrent en octobre 2005. Parmi les avancées de cette période favorable, qui a duré cinq ans, jusqu'en 2007, deux nous intéressent particulièrement : d'une part, la tutelle de l'armée sur les institutions démocratiques, source d'autoritarisme et de négationnisme, a été démantelée ; d'autre part, le gouvernement de l'AKP n'a pas entravé le travail de mémoire sur le passé du pays, notamment sur le génocide de 1915, qui a été engagé au sein de la société.

\section{Une société qui milite pour la reconnaissance}

Le point de départ de ce processus fut une conférence internationale sur les Arméniens ottomans réunissant des spécialistes de plusieurs pays, qui a eu lieu à Istanbul en 2005. Les circonstances du génocide y furent au centre des discussions. Les nationalistes ont tenté de la faire interdire, mais le Premier ministre Erdogan a soutenu sa tenue. Dans la foulée de la conférence, la société civile, y compris la communauté arménienne de Turquie, a commencé à s'exprimer publiquement sur son passé. Deux citoyens d'origine arménienne ont joué un rôle central dans cette libération de la parole : le journaliste et intellectuel Hrant Dink, grande figure, respectée par tous les démocrates, dont l'assassinat par un réseau de l'État profond, en janvier 2007, a bouleversé la société ; et l'avocate Fethiye Cetin, qui a publié un livre sur sa grand-mère arménienne. Cet ouvrage, devenu un best-seller, a provoqué un phénomène de coming-out de milliers de familles arméniennes qui avaient caché leur origine pour survivre pendant le génocide. On doit aussi citer le journaliste Hasan Cemal, dont l'ouvrage sur le génocide a fait sensation, car il est le petit-fils de Cemal Pacha, un des trois dirigeants Jeunes-Turcs qui ont planifié et organisé le génocide. Ainsi, la société a-t-elle entrepris un travail de mémoire et de réflexion critique sur son histoire et ses épisodes les plus tragiques, notamment les nettoyages ethniques en Anatolie, dont le plus grave fut le génocide armé- 
nien, mais qui ont aussi détruit d'autres populations non musulmanes, comme les Grecs pontiques ou les Assyro-Chaldéens entre 1915 et 1922. De tels processus ont révélé à l'opinion publique le rôle de ces "ingénieries démographiques", selon un concept utilisé par les démographes, dans la fondation de la République, la définition de son idéologie nationaliste-négationniste et de la nature mensongère du récit historique officiel. Le débat public s'est émancipé, le tabou concernant le génocide s'est désintégré.

Désormais, la référence au "génocide arménien" et le débat à ce sujet dans l'espace public, qui étaient considérés comme une "insulte à l'identité turque" selon l'article 301 du Code pénal, ne posent plus de problème. Depuis 2010, les acteurs de la société civile organisent des manifestations publiques dans les grandes villes, le 24 avril, date de la commémoration du génocide, pour réclamer sa reconnaissance par l'État turc. Des organisations de la diaspora arménienne y participent. La commémoration du centenaire du génocide, le 24 avril 2015, à Istanbul, fut particulièrement impressionnante, en présence de dizaines de milliers de personnes, des Turcs, des Arméniens et d'autres venues du Rwanda, d'Europe et des Amériques, de même que de nombreuses associations turques et arméniennes qui militent pour la reconnaissance du génocide par l'État turc. Dans le travail d'histoire et de mémoire que la société a entrepris depuis 2005 , les historiens locaux ont joué un rôle important'. Ils sont de plus en plus nombreux à se spécialiser sur le génocide. Ce processus a attiré l'attention des intellectuels arméniens, en Arménie et dans la diaspora. Ainsi, des historiens turcs et arméniens ont commencé à collaborer ${ }^{2}$, et des intellectuels de deux côtés, à dialoguer. Pour certains intellec- tuels arméniens, l'échange et le dialogue avec la société turque sont devenus des priorités pour la reconnaissance du génocide, ce point de vue étant partagé par leurs homologues turcs 3 . Ainsi, environ 150 intellectuels des deux côtés ont créé, à Paris, une association Le Collectif du rêve commun, dont l'objectif principal est de développer le dialogue entre les deux peuples ${ }^{4}$.

\section{Entre les dérapages du pouvoir et le soutien de la communauté internationale}

R. T. Erdogan, I'homme fort du pays et le gouvernement de I'AKP ont résolument tourné le dos à leur slogan initial de démocrates musulmans, après la troisième victoire électorale de I'AKP, en 2011. Le régime a régressé vers un autoritarisme nationaliste-musulman, reproduisant les réflexes de l'autorita-

risme nationaliste-laïque sur la durée, le travail de du passé, y compris un discours négationniste. Erdogan a déplacé la date de la commémoration du centenaire de la victoire des Ottomans aux Dardanelles, en 1915, afin d'escamoter celle du génocide des Arméniens. Le 19 mars mémoire et le débat public engagés dans la société civile, l'activisme de ses acteurs, de même que le discrédit international provoqué par son négationnisme, finiront par obliger l'État turc à abandonner son négationnisme inacceptable. dernier, il a prononcé un discours digne de la logorrhée négationniste du passé. Cependant, ce pouvoir, qui dérape et fait pression sur l'appareil judiciaire et les médias, n'a pas essayé d'entraver le travail de mémoire et le débat public sur le génocide. En fait, Erdogan, qui est un populiste avéré, prend ces postures en vue

1. Taner Akçam, Un Acte honteux. Le génocide arménien et la question de la responsabilité turque, Paris, Denoël, 2008. 2. Taner Akçam et Vahakn N. Dadrian, Jugement à Istanbul. Le procès du génocide des Arméniens, La Tour d'Aigues, éd. de l'Aube, 2015. 3. Michel Marian, Le Génocide arménien. De la mémoire outragée à la mémoire partagée, Paris, Albin Michel, 2015 ; Ahmet Insel, "La société turque face aux tabous de l'histoire", in Revue des Deux Mondes, avril 2015, pp. 93-102.

4. http://ourcommondream.org/nous-faisons-un-reve-ensemble. 


\section{REPÉRAGE}

des élections législatives du 7 juin 2015. Les sondages indiquant un certain effritement du vote AKP, il veut séduire l'électorat d'extrême droite. En même temps, il est conscient des effets catastrophiques du négationnisme au plan international. Le pouvoir fait de petits gestes : en 2014, Erdogan a présenté ses condoléances aux descendants des Arméniens ottomans ; en 2015, le Premier ministre Ahmet Davutoglu a déclaré que les Turcs partageaient la douleur des Arméniens. Le 24 avril 2015, un ministre du gouvernement a assisté à la Messe du centenaire, dans la grande église des arménienne d'Istanbul.

Dans la période récente, plusieurs reconnaissances officielles du génocide de 1915, accompagnées de critiques contre le négationnisme de l'État turc, ont sérieusement inquiété Ankara : celle du Vatican, à travers une critique sévère du négationnisme turc par le pape François, de même que celle du Parlement européen. Mais la prise de position la plus retentissante et embarrassante pour Ankara fut celle du président de la République allemande. À la reconnaissance du génocide par l'Allemagne, il a ajouté une seconde reconnaissance : celle de la "coresponsabilité" de son pays, dans ce génocide. En effet, alliée de l'Empire ottoman dans la guerre de 1914-18, I'Allemagne avait envoyé des militaires en Anatolie. Ils auraient pu intervenir et protéger les Arméniens, d'autant plus que des diplomates et des missionnaires ne cessaient d'alerter Berlin sur le calvaire des Arméniens. Il faut espérer que le geste du président allemand inspirera le président turc !

Sur la durée, le travail de mémoire et le débat public engagés dans la société civile, l'activisme de ses acteurs, de même que le discrédit international provoqué par son négationnisme, finiront par obliger l'État turc à abandonner son négationnisme inacceptable, sur les plans éthique, politique diplomatique, à reconnaître le génocide et à tendre la main à l'Arménie et à la diaspora arménienne. Cette reconnaissance doit être accompagnée de versements de réparations aux descendants des familles arméniennes d'Anatolie ; du rétablissement des relations diplomatiques entre Ankara et Erivan ; de l'ouverture de la frontière entre les deux pays; de l'accès de l'Arménie à des ports sur les côtes turques de la mer Noire et de la Méditerranée ; d'une aide conséquente au développement de l'économie arménienne et d'une action diplomatique déterminée et impartiale, afin de mettre fin aux hostilités entre l'Arménie et l'Azerbaïdjan.

Les segments de la société civile qui sont acquis à la cause de la reconnaissance sont encore minoritaires : $10 \%$ de la société dans son ensemble. Un autre chiffre plus encourageant concerne les jeunes : 33 \% d'entre eux sont pour la reconnaissance. Les acteurs et les partisans de la reconnaissance au sein de la société deviendront, tôt ou tard, majoritaires. Ils ont déjà remporté une victoire. Pour la première fois dans ce pays, un débat public sur une question majeure se déroule sur la base de principes universalistes. Si les Turcs veulent se débarrasser de l'autoritarisme nationaliste et vivre dans une démocratie et un État de droit, ils doivent se placer sur le terrain universaliste. Quant à l'État, il doit s'inspirer de sa société, en se plaçant également sur le terrain universaliste pour sortir du piège négationniste, faire acte de justice et de paix, en reconnaissant le génocide, en versant des réparations aux descendants des familles exterminées, en demandant pardon, en tendant la main à la nation et à l'État arméniens. 